\title{
Aseptic femur head necrosis revealing cushing's disease: A rare presentation
}

\author{
Zeineb Alaya*, Mouna Braham, Elyès Bouajina \\ Department of Rheumatology, Farhat Hached Hospital, Faculty of medicine of Sousse, Ibn el Jazzar Street, 4000 Sousse, Tunisia
}

\begin{abstract}
Background: Cushing's disease is an endocrine disorder and may be associated with non-traumatic osteonecrosis of the hip. We report the case of avascular necrosis of the femoral heads (AVNFH) as the presenting manifestation of Cushing's disease.

Case presentation: A 29-year-old male patient was referred to our department because of non-traumatic bilateral hip pain evolving for two years. The pain was associated with lameness when walking. He noticed a drop in libido since one year with erectile dysfunction. Physical examination revealed facio-truncal obesity, abdominal violaceous striae, dorsal hyper-kyphosis, a pain and limitation of internal rotation of the left hip with a Lequesne index of 16 . The standard radiography showed a loss of sphericity of the left femoral head with an aspect of eggshell. The MRI confirmed the diagnosis of a bilateral AVNFH. The baseline cortisol level was $287 \mathrm{ng} / \mathrm{ml}$. AVNFH as the presenting manifestation of Cushing's disease was suspected and confirmed by a pituitary MRI which revealed a pituitary adenoma. A discharge of the hips was indicated. The patient underwent surgical resection of the adenoma and was referred to the endocrinology department. The histopathological examination confirmed the diagnosis of pituitary adenoma (corticotrope adenoma). The patient has also received an intravenous perfusion of $5 \mathrm{mg}$ of Zoledronic acid. The follow up was marked by the regression of the symptoms of Cushing's disease and the hip pain.
\end{abstract}

Conclusion: AVNFH as the presenting manifestation of Cushing's disease is rarely described. Hence, it's needed to exclude endogenous hypercorticism in any patient with idiopathic osteonecrosis.

\section{Introduction}

Avascular necrosis of the femur head (AVNFH) is a debilitating disease, affecting mostly the middle-aged population (25-50 years) $[1,2]$. Its prevalence is on the rise and constitutes a multi-factorial and challenging clinical problem [3]. Il is considered to be the result of limited blood supply to this area with death of bone tissue in the femoral head, which can cause pain, limited joint mobility, fractures and in about $80 \%$ of untreated cases, its lead to collapse of the femoral head requiring surgical management [4-6]. This serious complication is typically associated with exogenous glucocorticoid treatment [7] and presents a rare feature of endogenous hypercortisolism [7]. The majority of the cases of AVNFH due to endogenous hypercortisolaemia required surgical intervention [6]. We report the case of bilateral AVNFH as the presenting manifestation of Cushing's disease, which was resolved after cure of pituitary adenoma.

\section{Case presentation}

A 29-year-old male patient was referred to our department because of bilateral hip pain evolving for two years, without a history of trauma. The pain was associated with lameness when walking. On the sexual side, he has noticed a drop in libido since one year with erectile dysfunction. Physical examination revealed facio-truncal obesity, abdominal violaceous striae (Figure 1), dorsal hyper-kyphosis (Figure 2), a pain and limitation of internal rotation of the left hip with a Lequesne index of 16. The standard radiography showed a loss of sphericity of the left femoral head with an aspect of eggshell (Figure 3). The MRI confirmed the diagnosis of a bilateral AVNFH (Figure 4). Biology has not objectified a biological inflammatory syndrome. The baseline cortisol level was $287 \mathrm{ng} / \mathrm{ml}$. Cushing's disease was suspected as the cause of this complication and confirmed by a pituitary MRI which revealed a pituitary adenoma. A total discharge of the hips was indicated. The patient underwent surgical resection of the adenoma in neurosurgery department and was referred to the endocrinology department for specialized care. The histopathological examination

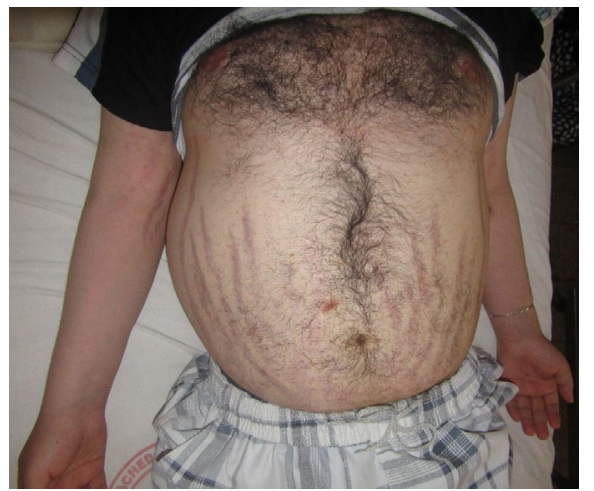

Figure 1. The image of the patient abdomen showed the truncal obesity with violaceous striae

${ }^{\star}$ Correspondence to: Zeineb Alaya, Department of Rheumatology, Farhat Hached Hospital, Faculty of medicine of Sousse, Ibn el Jazzar Street, 4000 Sousse, Tunisia, E-mail: zeineb_a@hotmail.fr

Key words: Avascular necrosis of femoral head, MRI, cushing's disease, pituitary adenoma.

Received: October 10, 2020; Accepted: October 22, 2020; Published: October 30,2020 


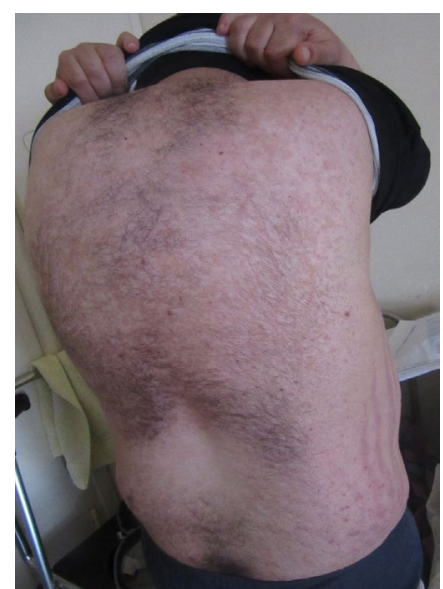

Figure 2. Posterior image of the patient showed the dorsal hyper-kyphosis

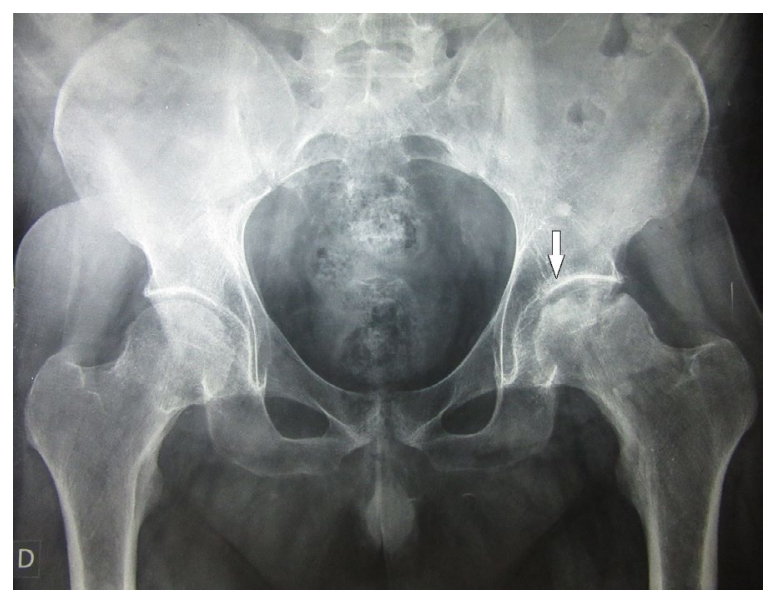

Figure 3. The pelvic X-ray showed a loss of sphericity of the left femoral head with an aspect of eggshell in favour of avascular necrosis of the left femoral head

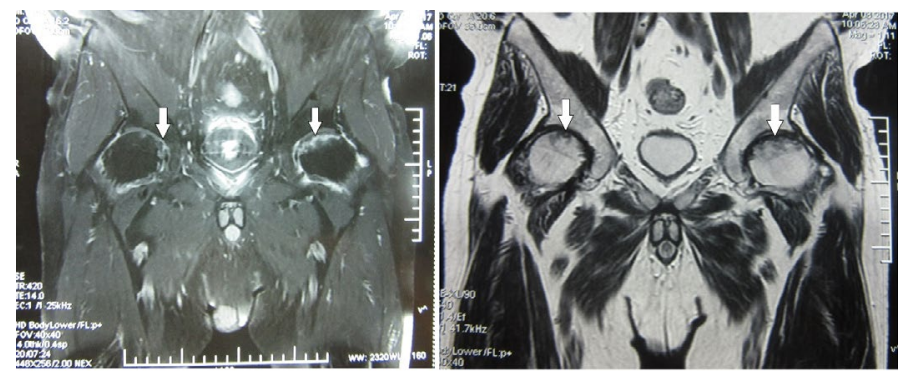

Figure 4. The MRI hips showed a bilateral avascular necrosis of the femoral heads with loss of sphericity and irregularity in both femoral heads

confirmed the diagnosis of a pituitary adenoma expressing intensively the ACTH in immunohistochemistry (corticotrope adenoma). The patient has also received an intravenous perfusion of $5 \mathrm{mg}$ of Zoledronic acid. The follow up was marked by the regression of the symptoms of Cushing's disease and the hip pain.

\section{Discussion}

AVNFH is a pathological state with various etiologies associated with a reduction in the vascular supply to the subchondral bone of the femoral head, leading to the osteocyte death and progressive collapse of the articular surface followed by degenerative arthritis of the hip joint [1]. This complication is frequently associated with exogenous glucocorticoid treatment [3]. In the literature, there have been few reports where AVNFH was the presenting feature of endogenous cortisol excess such us our case report $[8,9]$. In the largest series of patients with glucocorticoid-induced AVNFH, only 3 of 77 patients had evidence of endogenous steroid excess [10]. A possible mechanism of steroid-induced osteonecrosis is microvascular ischaemia due to intravascular thrombi formation and lipid microemboli leading to necrosis [11]. The relationship between glucocorticoid excess and the hypercoagulable state has been well known [7]. Another fact that glucocorticoids are associated with fat-cell hypertrophy in the bone marrow, which increases bone marrow pressure and compromises venous return [12]. Beckmann $\mathrm{R}$ et al. in 2014 reported that the treatment with low-molecular-weight heparin prevents avascular necrosis in animal models of steroid-induced osteonecrosis, this fact supports the theory that intravascular thrombosis plays a major role in its physiopathology [13].

Although AVNFH is reported typically in association with prolonged courses of high doses of glucocorticoids, it has been proved that up to $2.4 \%$ of patients on replacement doses of glucocorticoids (less than $5 \mathrm{mg}$ daily) can develop this complication of hypercortisolaemia [14].

Of all sites, the hip joint seems to be more susceptible to avascular necrosis, probably because of its limited blood supply through the delicate artery of the ligamentum teres, which is a terminal vessel arising from the obturator artery [7].

In the past, the diagnosis was done using conventional radiography, however, the radiologic abnormalities occur in advanced stages of the disease, when a therapeutic intervention would have little or no impact [11]. Recently, the diagnosis of AVNFH at the early stages is based on the MRI [4]. In our patient, the diagnosis was established in a stage of radiographic abnormalities and was confirmed by MRI.

Because AVNFH usually develops in the presence of trauma or other factors, such as exogenous glucocorticoids, alcoholism or liver disease, we concluded that the AVNFH diagnosed in our patient, without such predisposing risk factors, was due to endogenous hypercortisolism. Here, we report the case of a 29-year-old male with Cushing's disease due to a pituitary adenoma, which is among the most common intracranial neoplasms, with a prevalence of $15-20 \%$ in autopsy and imaging studies [15]. This disease was revealed in this case by a bilateral AVNFH as a complication of Cushing's disease.

In fact, our case illustrates that AVNFH, a serious complication, can be the presenting manifestation of Cushing's disease. Thus, this etiology should be suspected in every patient presenting with AVN in the absence of other risk factors, such as alcohol abuse or exogenous glucocorticoid use [9]. Also, AVNFH should be suspected in any patient with Cushing's disease presenting with sudden hip pain [9]. In such a case, an MRI must be practiced for confirmation because radiographic signs are usually absent in early stages [9].

In absence of treatment, AVNFH can lead to a complete collapse of the femoral head necessitating total hip replacement in up to $70 \%$ of patients [16]. In case of AVNFH due to endogenous hypercortisolaemia, the majority of the described patients were treated surgically with core decompression surgeries, osteotomies, or total hip arthroplasties $[9,17-$ 19]. In some cases, the medical therapies such as bisphosphonates, non-steroidal anti-inflammatory and low molecular weight heparin (LMWH), have been evaluated with varying clinical outcomes [20-22]. Our patient received an intravenous perfusion of $5 \mathrm{mg}$ of Zoledronic 
acid to stop the progression of the hip necrosis. There are some studies suggesting that statins can prevent osteonecrosis, but our patient was never exposed to this treatment [23].

\section{Conclusion}

Several studies in the literature have concluded that the AVNFH may be a manifestation of Cushing's disease, but AVNFH as the presenting manifestation of Cushing's disease is rarely described. Hence, it's needed to exclude endogenous hypercorticism in any patient with idiopathic osteonecrosis.

AVNFH in our patient did not necessitate hip surgery, and the patient's hypercortisolaemia was cured following ablation of the pituitary adenoma.

\section{Competing interests}

The author(s) declare that they have no competing interests.

\section{References}

1. Narayanan A, Khanchandani P, Borkar RM, Ambati CR, Roy A, et al. (2017) Avascular Necrosis of Femoral Head: A Metabolomic, Biophysical, Biochemical, Electron Microscopic and Histopathological Characterization. Sci Rep 7: 10721.

2. Kamal D, Traistaru R, Kamal CK, Alexandru DO, Mogoanta L, et al. (2014) A Case of Bilateral Aseptic Necrosis of the Femoral Head. Curr Health Sci J 40: 289-292. [Crossref]

3. Mont MA, Hungerford DS (1995) Non-traumatic avascular necrosis of the femoral head. J Bone Joint Surg Am 77: 459-474. [Crossref]

4. Assouline-Dayan Y, Chang C, Greenspan A, Shoenfeld Y, Gershwin ME (2002) Pathogenesis and natural history of osteonecrosis. Semin Arthritis Rheum 32: 94-124. [Crossref]

5. Weinstein RS (2012) Glucocorticoid-induced osteonecrosis. Endocrine 41: 183-190. [Crossref]

6. Kerachian MA, Seguin C, Harvey EJ (2009) Glucocorticoids in osteonecrosis of the femoral head: a new understanding of the mechanisms of action. J Steroid Biochem Mol Biol 114: 121-128. [Crossref]

7. Pazderska A, Crowther S, Govender P, Conlon KC, Sherlock M, et al (2016) Spontaneous resolution of avascular necrosis of femoral heads following cure of Cushing's syndrome. Endocrinol Diabetes Metab Case Rep 2016: 160015. [Crossref]

8. Takada J, Nagoya S, Kuwabara H, Kaya M, Yamashita T (2004) Rapidly destructive coxarthropathy with osteonecrosis and osteoporosis caused by Cushing's syndrome. Orthopedics 27: 1111-1113. [Crossref]
9. Koch CA, Tsigos C, Patronas NJ, Papanicolaou DA (1999) Cushing's disease presenting with avascular necrosis of the hip: an orthopedic emergency. J Clin Endocrinol Metab 84: 3010-3012.

10. Fisher DE, Bickel WH (1971) Corticosteroid-induced avascular necrosis. A clinical study of seventy-seven patients. J Bone Joint Surg Am 53: 859-873. [Crossref]

11. Glueck CJ, Freiberg R, Tracy T, Stroop D, Wang P (1997) Thrombophilia and hypofibrinolysis: pathophysiologies of osteonecrosis. Clin Orthop Relat Res 334: 4356. [Crossref]

12. Motomura G, Yamamoto T, Miyanishi K, Yamashita A, Sueishi K, et al. (2005) Bone marrow fat-cell enlargement in early steroid-induced osteonecrosis-histomorphometric study of autopsy cases. Pathol Res Pract 200: 807-811. [Crossref]

13. Beckmann R, Shaheen H, Kweider N, Ghassemi A, Fragoulis A, et al. (2014) Enoxaparin prevents steroid-related avascular necrosis of the femoral head. Scientific World Journal 2014: 347813. [Crossref]

14. Vreden SG, Hermus AR, van Liessum PA, Pieters GF, Smals AG, et al. (1991) Aseptic bone necrosis in patients on glucocorticoid replacement therapy. Neth J Med 39: 153 157. [Crossref]

15. Ezzat S, Asa SL, Couldwell WT, Barr CE, Dodge WE, et al. (2004) The prevalence of pituitary adenomas: a systematic review. Cancer 101: 613-619. [Crossref]

16. Mont MA, Jones LC, Hungerford DS (2006) Nontraumatic osteonecrosis of the femoral head: ten years later. J Bone Joint Surg Am 88: 1117-1132. [Crossref]

17. Saeed A, Bannan L (2012) Avascular necrosis of femoral heads post-adrenal surgery for Cushing's syndrome: a rare presentation. Ir J Med Sci 181: 263-264. [Crossref]

18. Ko JY, Chen SH, Chen CE, Chen SH, Eng HL (2004) Femoral head preservation in non-united femoral neck fracture and head osteonecrosis in Cushing's disease. $J$ Formos Med Assoc 103: 234-238. [Crossref]

19. Kobayashi S, Terayama K (1991) Coxarthrosis secondary to ischemic necrosis of the femoral head in Cushing's disease. Rev Chir Orthop Reparatrice Appar Mot 77: 362365. [Crossref]

20. Glueck CJ, Freiberg RA, Sieve L, Wang P (2005) Enoxaparin prevents progression of stages I and II osteonecrosis of the hip. Clin Orthop Relat Res 435: 164-170. [Crossref]

21. Agarwala S, Jain D, Joshi VR, Sule A (2005) Efficacy of alendronate, a bisphosphonate in the treatment of AVN of the hip. A prospective open-label study. Rheumatology (Oxford) 44: 352-359. [Crossref]

22. Albers A, Carli A, Routy B, Harvey EJ, Seguin C (2015) Treatment with acetylsalicylic acid prevents short to mid-term radiographic progression of nontraumatic osteonecrosis of the femoral head: a pilot study. Can J Surg 58: 198-205. [Crossref]

23. Pritchett JW (2001) Statin therapy decreases the risk of osteonecrosis in patients receiving steroids. Clin Orthop Relat Res 386: 173-178. [Crossref]

Copyright: (C2020 Alaya Z. This is an open-access article distributed under the terms of the Creative Commons Attribution License, which permits unrestricted use, distribution, and reproduction in any medium, provided the original author and source are credited. 